\title{
SYSTEMS ASPECTS OF LARGE-SCALE \\ SOLAR ENERGY CONVERSION
}

\author{
J.M. Weingart
}

May 1977

Research Memoranda are interim reports on research being conducted by the International Institute for Applied Systems Analysis, and as such receive only limited scientific review. Views or opinions contained herein do not necessarily represent those of the Institute or of the National Member Organizations supporting the Institute. 


\section{$\underline{\text { PREFACE }}$}

In examining the potential role of solar energy conversion as a gobal energy option the author has been led to issues which ultimately require the tools of systems analysis in their clarification. Such issues are not only technical in nature; they impinge on both economic and policy-related matters. In particular, much more needs to be known about the behavior of very large integrated solar energy conversion systems in order to insure appropriate and timely policy for the development and use of these important options. In this paper the author therefore has attempted to present a new set of challenges, and the rationale for taking up these challenges, to the systems analysis community.

The author was invited to present this paper to the International Symposium on New Trends in Systems Analysis. This conference of the Institut de Recherche d'Informatique d'Automatique was held in December 13-17, 1976, at Versailles, France. 


\section{$\underline{\text { ABSTRACT }}$}

With a view to the potential role of solar energy as a global energy option, the presently known solar energy technologies are employed to contribute to the world energy supply. Such a global solar energy supply system would evolve in stages of development, proceeding from local use of solar energy to regional and global systems. The initial stage would include local low-temperature applications for heating purposes, and the embedding of small amounts of solar electric generation capacity in the existing electric grids. Regional interconnections of solar electric power generation would be followed by increasing production of solar fuels in locations with favorable insolation, and by long-distance transport of these fuels. It turns out that much more needs to be known about the behavior of very large integrated solar energy conversion systems. Market penetration calculations indicate that it takes roughly five decades for a major source of energy to be developed and used on a truly significant scale. It therefore would be necessary to initiate large-scale deployment of solar energy perhaps 50 years or more before fossil resources are finally depleted. 


$$
\text { - }
$$




\title{
SYSTEMS ASPECTS OF LARGE-SCALE
}

\author{
SOLAR ENERGY CONVERSION
}

\section{INTRODUCTION}

On November 20, 1959, the General Assembly of the United Nations unanimously approved the Declaration of the Rights of the child, a statement affirming international recognition of and growing commitment to the concept of a "birthright" for all humans. Among other things, the Declaration affirms:

The child shall enjoy special protection, and shall be given opportunities and facilities ... to enable him to develop physically, mentally, morally, spiritually and socially in a healthy and normal manner and in conditions of freedom and dignity.

One could add that such conditions ought to prevail for the entirety of a human lifetime, not just for childhood. Global development goals that do not include provision of such a birthright to all humans are inconsistent with any concept of a decent world.

Achieving such goals will under the best of circumstances be very difficult and almost certainly require several generations at the least.

Although it is not by itself a sufficient guarantee for a livable world for all inhabitants, a minimum per capita energy level higher than the present one is nevertheless a prerequisite. Present per capita energy use is at the rate of $2 \mathrm{~kW}(\mathrm{th}), \mathrm{a}$ statistic which obscures the fact that much of the world population is living at a subsistence level of a few hundred watts. It is the non-uniform distribution of energy use, coupled with the wide variance in efficiency of use, which accounts in part for the misery of much of the present world population.

While it can be argued that the industrialized countries could become more efficient in energy use by a factor of two or more over a three decade period, it is inevitable that a decent world will require more energy in the future, not less. There are several factors which make this so. First, the momentum in growth of world population nill lead to approximately six billion people shortly after the turn of the century, and this would almost certainly become ten billion or more within the coming century. In addition, the industrialized nations will continue to grow in their demand for energy, although perhaps at a somewhat lower rate than in the past. Finally, the needs of the emerging regions of the world for energy will dictate a rapid growth in demand if prosperity in even modest terms is to be achieved. 
Present world energy use (of primary sources) is at the rate of $7.5 \mathrm{TW}(\mathrm{th})$. A world of ten billion people $\left(10^{10}\right)$ living at the $5 \mathrm{~kW}(\mathrm{th})$ per capita standard of Western Europe would correspond to an almost order of magnitude increase to $50 \mathrm{TW}(\mathrm{th})$, and could result from an average rate of growth in the product of population and per capita energy use of two per cent per year over the next century $\left(1.02^{100}=7.24\right)$. An increase by a factor of 2.5 in per capita energy use over this period could occur throuqh a dramatic continuous reduction in the population growth rate; increased affluence will also come from very large increases in the end use efficiency in the developing regions. At the same time, human settlement patterns will continue to move in the direction of increased urbanization and highdensity settlements [1] and energy use will be increasingly dominated by the consumption of secondary energy carriers (pressurized hot water, electricity and fuels).

The transition over a century or so to such a level of global affluence and stabilized population would be extremely difficult in a world in which oil and gas were both unlimited and cheap. But if the enormous problem of improving the conditions of life for much of the present and future world population seems difficult, it is compounded by the pressures of the inevitable (?) trends towards higher population and higher urban populations, with accompanying non-linear increases in the difficulties of production and delivery of adequate food, energy, housing, health care and education. In addition we face the certain prospect of exhaustion of most of the world's most useful and, until recently, least expensive sources of energy--oil and natural gas. This will take place over the coming four to five decades, along with the problems the high prices for these increasingly scarce commodities will create.

Hence, as we attempt to confront the increasingly urgent problems of world human needs, we must also initiate and carry out a world-wide transition from primary reliance on fossil fuels to some mix of long-term sources for the production of heat, electricity and synthetic fuels. While the rate and scale of such a transition will certainly vary from place to place, depending on patterns of needs, resources, wealth, industrialization, and so forth, this transition will ultimately be global and it will be essentially complete within a century. Although there is some argument regarding the extent of recoverable resources of coal, oil and gas, the available resources appear to be in the range of 1500 to $3000 \mathrm{TW}$-years, sufficient for world energy needs growing at two per cent per year for roughly one century. Oil and gas would of course be exhausted much sooner, perhaps in 40 to 50 years. What is therefore required is a smooth transition to reliance on the long-term global options. There are exactly four in number.

These primary energy sources, sufficient to provide a livable world of ten billion people for hundreds of centuries at the least, and essentially forever in principle, are the fission sources (via the breeder reactor), the fusion sources 
(lithium and deuterium), geothermal energy and the sun. Unfortunately we must rule out fusion as an option we can count on, since scientific feasibility has not yet been established, although many experts are convinced that this will be achieved. Geothermal energy is sufficient for world energy needs only in the form of heat in dry rocks and magma. Moreover, estimates indicate a technically feasible steady-state secondary energy production rate of less than one $T W(t h)$ from such sources if the presently unresolved technical problems can be solved.

Sunlight and fission are all that remain. Certainly the lion's share of attention has been, in terms of science, industry and policy, directed towards the development of largescale nuclear electricity and ultimately, as suggested by W. Häfele [2] and others, for provision of synthetic fuels as well. While in purely technical terms we are more or less assured of being able to develop fission systems for deployment at the global level, the institutional issues are by no means resolved. New approaches to potential problems related to reactor safety, radioactive waste management and protection from terrorism will be required in order to deploy fission systems at the global level. Possible approaches have been indicated by $W$. Häfele [3] and $C$. Marchetti [4] to decoupling society and the technologies which will serve society with secondary energy forms.

Both direct and indirect forms of solar energy can be used to produce secondary energy carriers. However, the use of the indirect sources (wind, waves, thermal gradients in the oceans, hydraulic potential and the osmotic potential of fresh water flowing into the oceans) appears limited to something on the order of $5 \mathrm{TW}$. Only the direct use of the solar irradiance is capable of providing upwards of $50 \mathrm{TW}(\mathrm{th})$ continuously. Tables 1 and 2 indicate the scale of the problem. Furthermore, as discussed below, provision of energy at the level of many tens of terawatts is possible only through a global deployment of solar conversion facilities in the sunny parts of the world, connected with the demand centers through transmission over long distances of fuels and electricity. Requirements for dedicated land will be on the order of a million square kilometers of sunny (arid wasteland and deserts) regions distributed around the world.

An important aspect of the transition to a world in which non-fossil options provide the majority of energy needs will be the timing of this shift. We know that it requires roughly five decades for a major source of energy to be developed and used on a truly significant scale. Hence, the initiation of large-scale development and deployment of the long-term alternatives must begin perhaps 50 years or more in advance of the ultimate depletion of the fossil resources. We are perhaps two decades at most into this for fission systems, and only a few years into the development of large-scale solar systems. Even if we could count on fusion, initiation of large-scale 
Table 1. Present patterns of land use and potential solar energy conversion area requirements

\begin{tabular}{llcc}
\hline Uses & Region & $10^{6} \mathrm{~km}^{2}$ & \%otal \\
\hline Used & Human settlements & 0.4 & 0.3 \\
fully & Arable land & 13.0 & 8.8 \\
\hline $\begin{array}{l}\text { Partial } \\
\text { use }\end{array}$ & $\begin{array}{l}\text { Pastures } \\
\text { Forests }\end{array}$ & 21.3 & 14.3 \\
\hline Usable & (not practical) & 35.3 & 23.8 \\
unused & Wasteland, desert, & 3.9 & 2.6 \\
& mountains & 62.1 & 41.8 \\
& Uninhabited islands & 12.5 & 8.4 \\
\hline and polar regions & & \\
\hline Total & Global land area & 148.5 & 100.0 \\
\hline Solar & 7.5 TW & 0.15 & 0.1 \\
(50 $/ \mathrm{m}^{2}$ ) & 50.0 & 1.0 & 0.7 \\
& 400.0 & 8.0 & 5.4 \\
\hline
\end{tabular}

Table 2. Area requirements for solar energy conversion for various combinations of population and per capita energy demand

\begin{tabular}{lcccc}
\hline Date & $\begin{array}{c}\text { Population } \\
10^{9}\end{array}$ & $\begin{array}{c}\text { Energy/cap } \\
\mathrm{kW}(\mathrm{th})\end{array}$ & $\begin{array}{c}\text { World Energy } \\
\mathrm{TW}(\mathrm{th})\end{array}$ & $\begin{array}{c}\text { Solar Area } \\
10^{6} \mathrm{~km}^{2}\end{array}$ \\
\hline Now & 4 & 2 & 7.5 & 0.15 \\
\hline 2076 & 10 & 5 & 50.0 & 1.0 \\
\hline ??? & 20 & 20 & 400.0 & 8.0 \\
\hline
\end{tabular}


commercial systems is unlikely, in the most optimistic of scenarios, to begin before the early part of the next century. Therefore, we must consider the global deployment of solar conversion systems at the same level of concern as we consider the fission option.

The potential consequences of such large-scale use are of special concern. From experience in the field of fission power we know that in the beginning of the technological development period, the large-scale aspects of the technology are often not thoroughly examined (or even perceived). Only when large-scale activity commences do such considerations become visible and important. From hindsight we realize that the development of a strong, systems-oriented technology assessment of the fission option might have made a substantial contribution to the recognition and resolution of problems which are now inhibiting the use of such technologies.

Solar energy conversion systems will be no exception to the rule that the large-scale use of any new technology bears unexpected and often undesired consequences. Although there appears to be a popular mythology that the use of sunlight is completely "clean", this mythology will fall as large areas of desert lands are covered with machines and valleys are flooded to provide needed hydroelectric storage facilities to permit full use of solar generated electricity. Even the possibilities of climatic modification appear when we consider covering upwards of a million square kilometers of sunny land with solar conversion machines [5].

In considering the possible use of solar conversion on this scale, a number of questions come to mind. For example, it has been only recently that the production of electricity from large (1000 $\mathrm{MW}(\mathrm{e})$ ) solar power plants and the production of synthetic fuels from both fission and solar facilities has been examined. Even less attention has been paid to how a mix of non-fossil energy sources could be integrated into large thermal (district heating), electrical and fuel networks. Yet, without such a systems perspecitve, it is not easy to see how such options fit into an overall long-term energy strategy. This is particularly true of solar energy conversion where we cannot control the energy input to the conversion machines. At present we do not have a clear idea of how an integrated electrical utility would operate when a substantial portion of installed capacity is in the form of solar power plants, nor do we understand the trade-offs involved among various solar plant siting strategies (and the effects of dispersion) and the requirements for energy storage and backup generation capacity to guarantee a specified level of overall system reliability. A similar lack of systems understanding applies to the impact of large numbers of solar heated buildings on the demand profile of electric and gas utilities.

These and other issues must be better understood if appropriate public support as well as industrial development 
and commercialization programs are to be initiated and supported for the necessary decades. In particular, we must concern ourselves with the following classes of issues in which systems considerations will be important, and where new methodologies may have to be developed:

(1) operation and optimization of integrated energy systems in which solar conversion elements are embedded; (This is especially improtant for electrical utility systems.)

(2) the complementary problem of embedding such facilities in the landscape, and the effect of alternative siting strategies on systems operation and economics; (Important since dispersed but interconnected solar systems require reduced backup and storage capacity relative to single site strategies.)

(3) market penetration dynamics--assessment of the maximum rate and scale at which new energy systems technologies, including solar, can penetrate the energy marketplace;

(4) technology assessment in the broadest sense, including an examination of environmental and social consequences of alternative energy strategies;

(5) establishment of a rational basis for intercomparison of large-scale energy systems options (not to take the place of public or private debate but to provide an explicit framework within which decisions and debate can take place);

(6) determination of the "resilience" of alternative energy strategies to uncertainty, disruption, geopolitical shifts and so forth.

Each of these will be discussed in turn, after a brief review of the solar resource, technological options for solar energy conversion and some possibilities for global use of these options. It is fair to say that at this point in time, many questions will be raised and few will be immediately answered. However, finding the right questions will be the hardest part of the task for future analyses.

\section{SOLAR ENERGY AS A RESOURCE}

The solar resource is unique in that it is a power resource. It is available at a rate determined by the surface temperature (5900K) and angular size of the sun, the properties of the atmosphere and the earth/sun geometry as seen from a specific place on the globe at a given time. Due to the presence of the atmosphere--a turbulent scattering medium--the maximum power density at the surface of the earth is approximately $1.0 \mathrm{~kW} / \mathrm{m}^{2}$ and is composed of both diffuse (scattered) and direct (focusable) radiation whose ratio depends on the state of the atmosphere. Under very clear sky conditions, direct beam 
radiation will constitute as much as 90 per cent of the total irradiance; under conditions typical of central Europe in winter the direct component will often be negligible. The annual average solar energy on the ground will vary from 2 to $6 \mathrm{kWh} / \mathrm{m}^{2}$-day over the world, the former figure typical of Northern Europe, the latter typical of sunny arid and desert regions. In clear sky environments the direct beam radiation can average 7 to $8 \mathrm{kWh} / \mathrm{m}^{2}$-day on a surface continuously oriented towards the sun, and it is this resource which will be so important in any true global solar energy scheme.

The statistics of the insolation time series will vary as a function of location and time of year and will reflect the product of a geometrically determined incident radiation and the stochastic filtering effects of the atmosphere. The combination of the diurnal and seasonal cycles and these stochastic fluctuations make it imperative that energy storage elements and, possibly, long-distance interconnection of solar electric facilities be used to meet systems constraints of economics and reliability. (Further details of the solar resource appear in standard references [6].) Table 3 indicates that solar derived fuels $\left(\mathrm{H}_{2}\right)$ and electricity can be produced at a thermal equivalent rate of about $50 \mathrm{~W} / \mathrm{m}^{2}$ (dedicated land area) in the sunny, clear sky regions of the world.

Table 3. Net production of secondary energy forms and thermal equivalent from solar energy conversion. Ground cover ratio of 0.4 to 0.5 assumed for STEC, solar thermal hydrogen; 0.8 for PV

\begin{tabular}{|c|c|c|c|c|c|}
\hline Solar Resource & Technology & Efficiency & \multicolumn{3}{|c|}{$\begin{array}{l}\text { Net Output } \\
\left(\mathrm{w} / \mathrm{m}^{2}\right)\end{array}$} \\
\hline \multirow[t]{2}{*}{$\begin{array}{l}250-300 \mathrm{~W} / \mathrm{m}^{2} \\
\text { Direct beam }\end{array}$} & STEC & $0.2-0.35$ & $\begin{array}{l}20 \\
60\end{array}$ & $\begin{array}{l}50 \\
-\quad 150\end{array}$ & $\begin{array}{l}(e) \\
(t h)\end{array}$ \\
\hline & $\begin{array}{l}\text { Solar ther- } \\
\text { mal hydrogen }\end{array}$ & $0.2-0.6$ & 20 & -90 & $(t h)$ \\
\hline \multirow[t]{3}{*}{$\begin{array}{l}80-250 \mathrm{~W} / \mathrm{m}^{2} \\
\text { Global radiation }\end{array}$} & Photovoltaic & $0.1-0.25$ & $\begin{array}{r}6 \\
18\end{array}$ & $\begin{array}{lr}- & 50 \\
- & 150\end{array}$ & $\begin{array}{l}(e) \\
(t h)\end{array}$ \\
\hline & $\begin{array}{l}\text { Biocon- } \\
\text { version }\end{array}$ & 0.1 & 6 & -20 & $(t h)$ \\
\hline & $\begin{array}{l}\text { Low tempera- } \\
\text { ture heat. }\end{array}$ & $0.3-0.5$ & 25 & -125 & $(t h)$ \\
\hline
\end{tabular}


Solar energy must first be converted into other forms of energy prior to use by society. The indirect forms of solar energy, such as wind and waves, will be converted initially to mechanical energy (shaft horsepower) and then to electricity or, possibly, via refrigeration cycles to liquid air. As discussed earlier, the total potential of the indirect solar options is on the order of perhaps $5 \mathrm{TW}(\mathrm{th})$. The direct use of solar energy is possible via a number of thermodynamic pathways, as illustrated in Figure 1. Once sunlight is converted directly to heat, electricity or a chemical fuel, it can then be used in an energy system such as that indicated schematically in Figure 2. All energy systems, whether they are bears, breeder reactors or Maseratis, are composed of four basic building blocks. These are energy conversion, energy storage, energy transport and power conditioning. The final element refers to the hardware for control of flows,

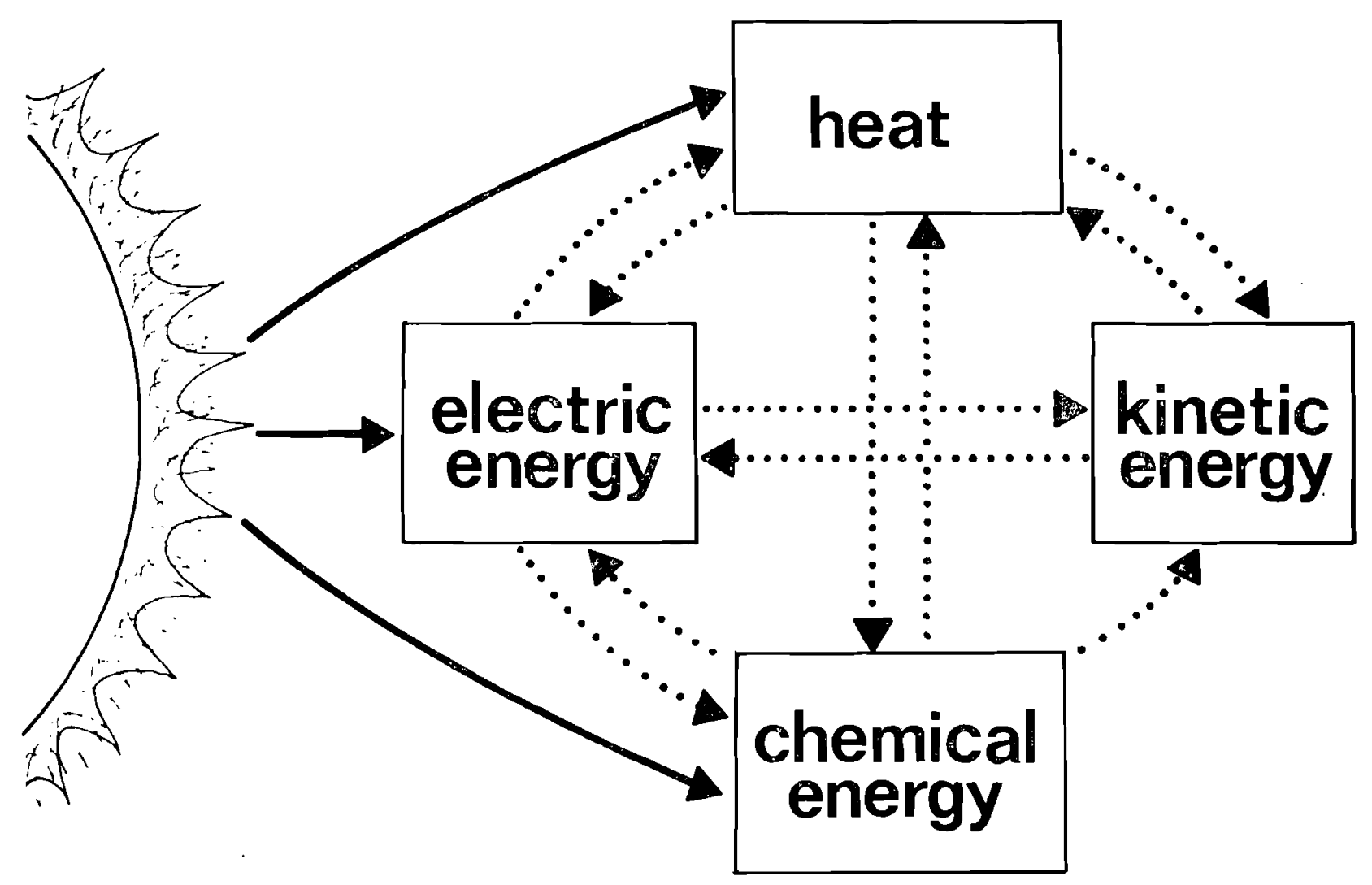

Figure 1. Direct conversion of sunlight to useful secondary energy forms via various thermodynamic pathways 


\section{SUNLIGHT}

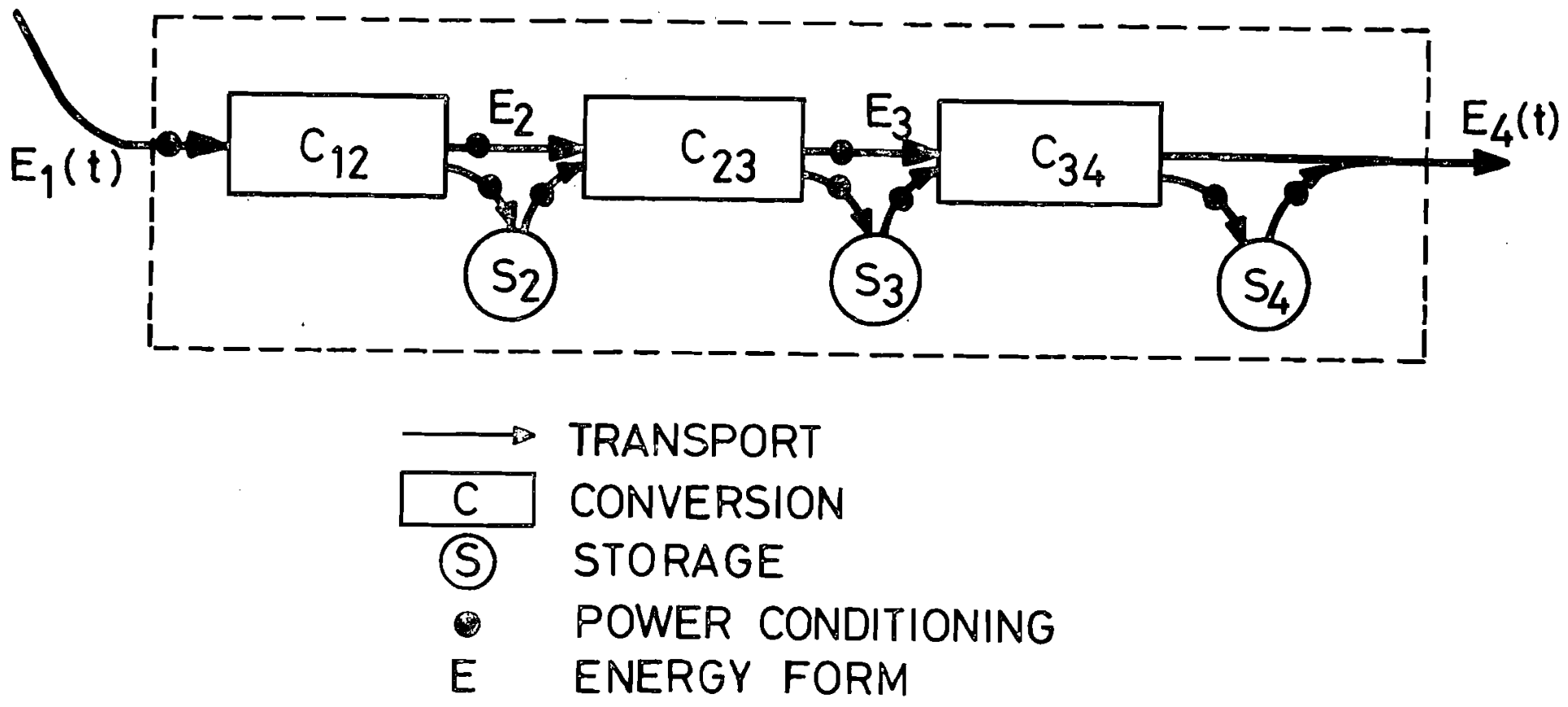

Figure 2. Generalized schematic representation of a solar energy conversion system

frequency stabilization, AC/DC conversion, voltage control, pressure control, etc. in various parts of an energy system, and to the software (the brains) for operation of the system. Hence, a solar energy system is one in which the "front end" conversion element is one in which sunlight is converted to some other form of energy such as heat, electricity or chemical energy.

The very high thermodynamic quality of sunlight, even after passing through a clear atmosphere, permits generation of heat at temperatures in excess of $3000^{\circ}$ (as demonstrated in the magnificent French solar furnace at Odeillo). In fact, 
with a suitable absorbing cavity it is possible to generate higher temperatures using a plastic Fresnel lens, available for a few dollars, than is possible with the most advanced designs of high temperature reactors. Hence, sunlight is a suitable source of thermal energy over the temperature range likely to be of interest for considerable time, and is suitable for operation of Rankine cycle (steam) and Brayton cycle (gas or air) turbines for the generation of electricity or the thermochemical production of hydrogen and oxygen from water. A particular technological format for such conversion is the "central receiver" system, in which tracking mirrors or heliostats concentrate solar radiation on an absorber atop a tower to generate steam or hot air to operate a turbine. A $100 \mathrm{MW}(\mathrm{e})$ sun-following plant would require roughly 15,000 such heliostats, each about $40 \mathrm{~m}^{2}$ in area with an absorber atop a. 200 to $250 \mathrm{~m}$ high tower. Such a system (Figure 3) would generate power at the rated capacity for eight to ten hours per day in

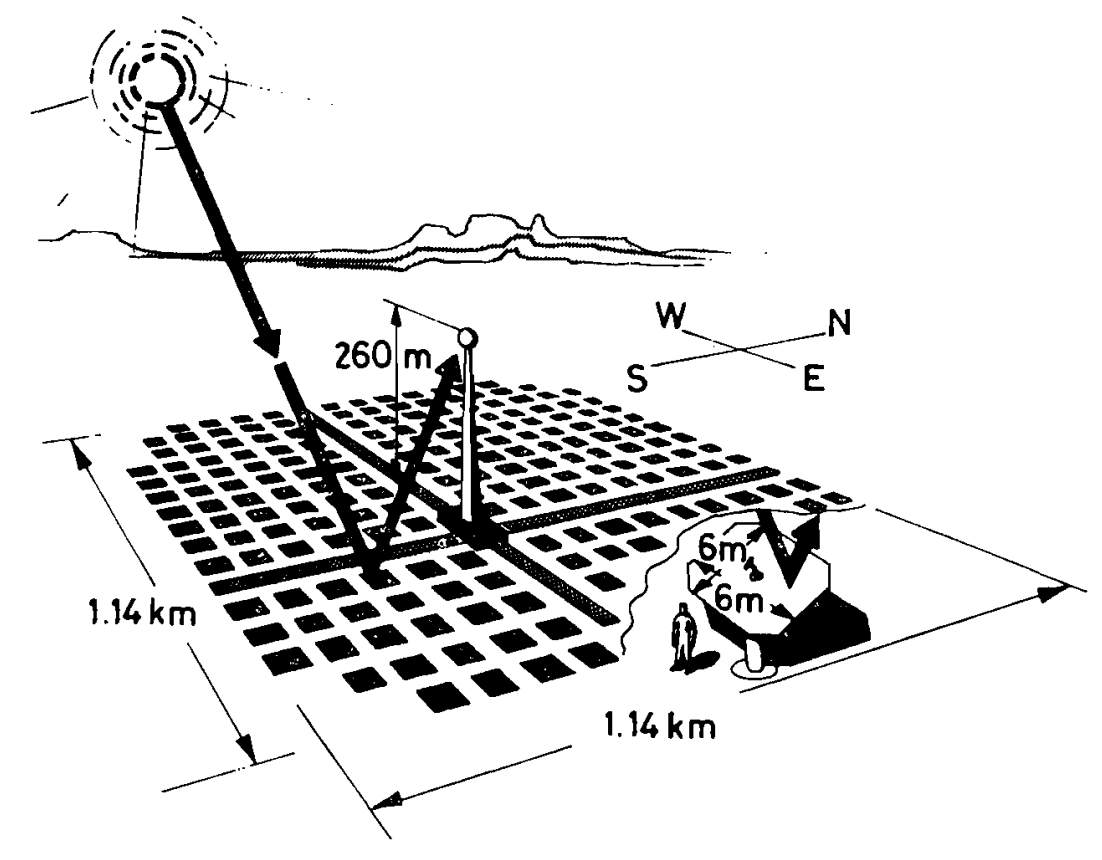

Figure 3. Conceptual form of a solar thermal electric power plant with a radiation receiver atop a tower in a mirror field 
sunny regions, with a small amount of storage to buffer the turbine against rapid changes in steam or hot gas conditions. Such systems are under development in the United states [7]; a 10 MW(e) plant will be on line at the end of this decade and a 100 MW(e) system should be in operation in the mideighties. A similar effort is now being considered in France. Some of the possible systems configurations are shown in Figure 4. A second conversion approach involves direct conversion of sunlight to electricity via photovoltaic elements or "solar cells". Such units respond to sunlight independent of whether it is direct or diffuse and are therefore suitable for siting in regions of low direct beam insolation. Their development as economically interesting options is being pursued actively in a number of countries including the US and the Federal Republic of Germany. Finally, for the purposes of this paper, solar fuel production can proceed either via photochemical/biological routes or by conversion of either electricity (via electrolysis) or heat (thermochemical). Interestingly enough, the prodcution of hydrogen from sunlight in sunny regions remote from Europe (perhaps $5000 \mathrm{~km}$ distant). may result in a more economic approach to heating of buildings in Europe than on-site use of solar collectors and associated

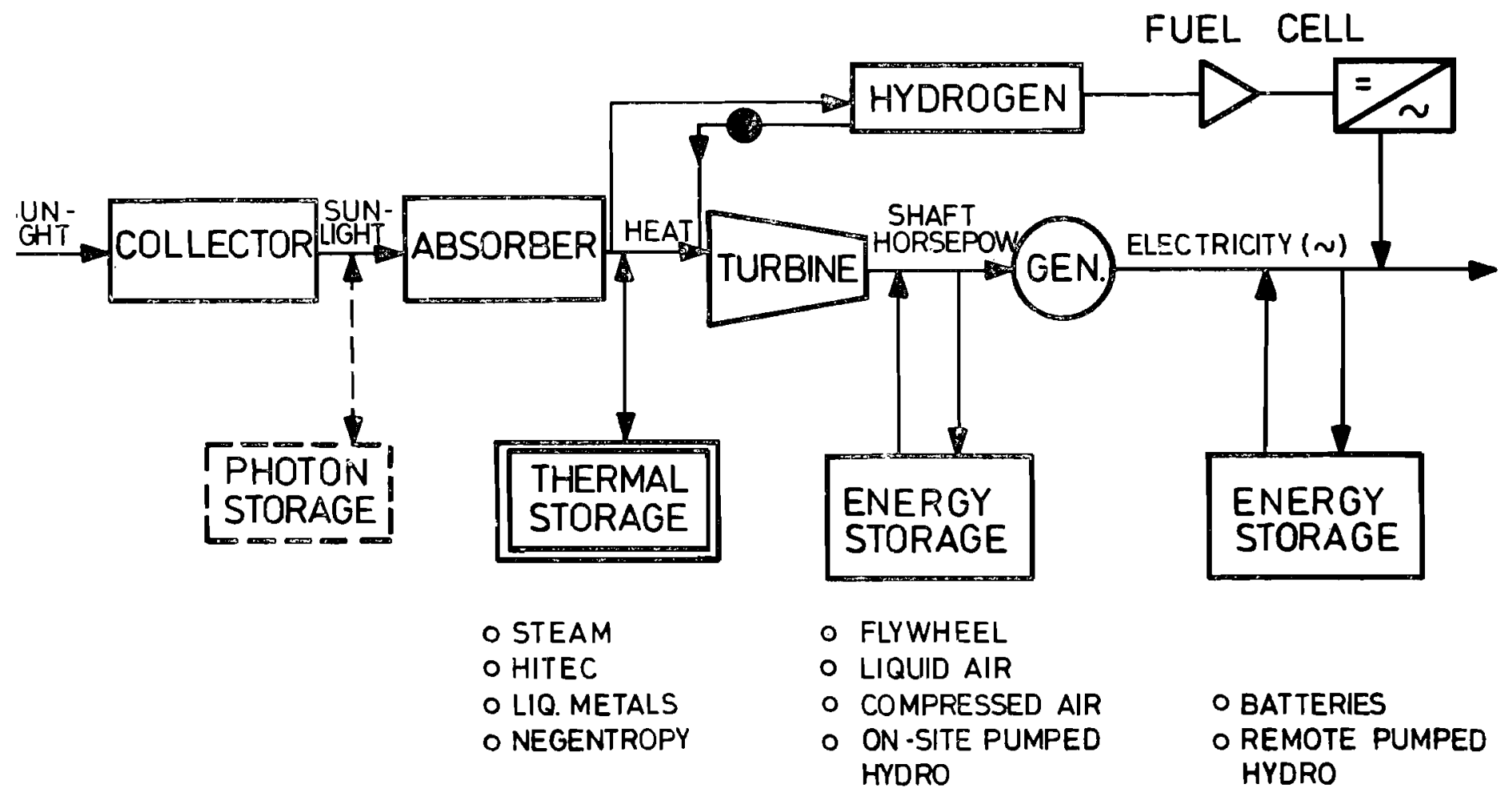

Figure 4. Possible combinations of solar thermal energy conversion to electricity and fuel 
storage, transport and control elements. Although a detailed review of the systems options is inappropriate here, the range of expected costs for solar generated hydrogen transported to Europe is shown for electrolytic and thermochemical processes in Tables 4 and 5 .

Table 4. Electrolytic hydrogen from sunlight. Estimates using best available data and cost projections for the cost of producing hydrogen by a combination of solar thermal electricity and electrolysis.

\begin{tabular}{lccc}
\hline & Case 1 & Case 2 & Case 0 \\
\hline STEC (\$kW $(\mathrm{e}))$ & 700 & 1400 & 500 \\
Electrolysis $\left(\$ / \mathrm{kW}_{\mathrm{H}}\right)$ & 400 & 500 & 100 \\
System load factor & 0.40 & 0.25 & 0.4 \\
\hline $\mathrm{H}_{2}$ cost (\$/bbl equiv.) & $55 *$ & $211 *$ & $30 *$ \\
$* 10 \%$ fixed charge rate & & & \\
\hline
\end{tabular}

Table 5. Thermochemical hydrogen from sunlight. Estimates of the likely range of costs for the production of hydrogen by solar thermo-chemical processes using current estimates of almost certain (Case 1), highly likely (Case 2) and possible but optimistic (Case 3) costs of the system elements

\begin{tabular}{lccc}
\hline & Case 1 & Case 2 & Case 3 \\
\hline Net efficiency & 0.10 & 0.25 & 0.64 \\
System load factor & 0.25 & 0.35 & 0.40 \\
$\$ / \mathrm{kW}_{\mathrm{H}}$ & & & \\
Heliostats & 750 & 240 & 75 \\
BOP & 100 & 75 & 45 \\
Thermochemical & 400 & 200 & 100 \\
\hline Total capital cost & 1250 & 515 & 220 \\
\hline $\begin{array}{l}\text { \$bbl equiv. } \\
\text { i }=0.10(0.15)\end{array}$ & 100 & 30 & 11 \\
\hline
\end{tabular}


The world is evolving towards a system in which most of the energy-related needs will eventually be provided through the distribution of electricity and fuels. As oil and gas are depleted, other globally transportable fuels must take their place. Hydrogen, methane, alcohols, ammonia and liquid air (the last not strictly a fuel but a negentropy carrier) have all been proposed as the interface between the large-scale primary energy sources and the evolving pattern of end uses. Even at the $50 \mathrm{TW}(\mathrm{th})$ level of a world of $10^{10}$ people and $5 \mathrm{~kW}(\mathrm{th})$ per person, it is possible to supply this demand (forever) from the direct use of solar energy. The structure of a global solar energy system would involve hierarchies, but it would depend on the availability of long-distance electricity transport. and global fuel transport. The present average distance tor bulk electricity transport is $100 \mathrm{~km}$ but the trends, through high voltage DC transmission, are towards distances on the order of $1000 \mathrm{~km}$ or more, and longer-distance transmission may be a reality at the time needed (after the year 2000). Transmission of liquid fuels is now a global operation, and the oil business is the largest activity in the world economy. Pipeline transmission of synthetic fuels such as hydrogen will be possible for distances up to perhaps $5000 \mathrm{~km}$. Hence, a global solar scenario would include the following features:

(1) local use of solar heating where economics and environmental conditions permit;

(2) solar electric power generation units located throughout the world, primarily in sunny regions, interconnected over distances of perhaps 1000 to $2000 \mathrm{~km}$ and more;

(3) solar fuel (hydrogen?) production units in the sunny parts of the world providing hydrogen and other energy carriers via pipeline and perhaps cryotanker to the entire world.

By making use of the arid and desert wastelands, we can limit the total area required to roughly $20 \mathrm{~m}^{2} / \mathrm{kW}(\mathrm{th})$ for the produced secondary energy, corresponding to $10^{6} \mathrm{~km}^{2}$ to provide a world at an order of magnitude greater total demand than today. This picture has a certain internal consistency. In order for the solar option to be a global option, it has to provide primarily fuels and electricity. By virtue of the increasing capacity for economic and reliable long-distance transport of these carriers, sunny regions are possible for siting the bulk of the facilities. In addition, global development patterns will require land for settlements and agriculture as well as recreation, forestry and ecological diversity. However, even in a scheme of 40 billion people on the planet, C.A. Doxiadis [1] has pointed out that the arid and desert lands will remain essentially uninhabited and unproductive. A global solar option is consistent with this view. 
Of course, within such a system solar conversion elements may be embedded locally, and many countries may want to have some fraction of the production capacity within their boundaries.

Such a scenario would have the following attributes, which to some should appear attractive (but further analysis is really required to examine these in detail):

(1) dispersion of solar fuel and electricity sources over much of the world, minimizing the possibility of embargo (the world would have to embargo itself!);

(2) dispersion of electric production would significantly reduce the need for backup generation capacity and storage requirements as well as permit the minimum solar electricity production costs compatible with the technology at a given time;

(3) production of hydrogen or other fuels would permit storage underground in natural structures (e.g. depleted oil and gas fields, aquifers) permitting creation of reserves to buffer against political and technical disruption of production units;

(4) such a system would virtually bypass the hazards ascribed to a global nuclear fission system. Disruption of the solar units would have no environmental consequences, no wastes are produced, and the systems would have no military uses in the direct sense (which may, in part, account for the relative lack of interest in solar energy systems for the past several decades);

(5) the resource is totally non-depletable; hence, true stability in secondary energy production would be assured. (These systems would be the equivalent of giant, nondepletable fuel fields with a production rate limited to $50 \mathrm{~W} / \mathrm{m}^{2}$ of dedicated land.)

There are other aspects worth mentioning. It appears that the large solar electric and fuel systems will require primarily concrete, steel and sand in their construction. Although a detailed examination of the materials requirements for the high temperature portion of the system is required, it appears that there will be no fundamental materials problems with such systems. Hence, in constant costs, the cost of such systems should continue to decrease over time, approaching some asymptotic limit. This is thought to be about $\$ 500 \mathrm{kw}(\mathrm{e})$ for solar thermal electric plants. Finally, the conversion of sunlight and water into hydrogen and oxygen, with subsequent recombination into pure water, is in principle a highly attractive global energy system, although the consequences of operation of such a system remain to be evaluated. 
We should also realize that the development, construction and operation of such a system would constitute the largest technical, engineering and economic venture of the world. It would dwarf anything undertaken to date, and it would clearly require and perhaps forge new alliances among nations and new institutions to manage this system. But it should be pointed out that the alternative--a global fission system to provide these same $50 \mathrm{TW}$ to the world, would require investments and engineering and institutional activities just as large. In other words, we are stuck (probably) with the need to create such a giant energy infrastructure; the relation of solar and non-solar options within such a structure is still not well understood.

of course, such a system would not be created from the top down. It would evolve in stages of development. The initial stage, lasting into the 1990's, would include the construction of hundreds of thousands of buildings with solar thermal equipment, and the embedding of small amounts of solar electric generation capacity in the electrical grids of the industrialized nations (those which had suitable high insolation sites) to perhaps three per cent of total capacity. From the midnineties into the first decade(s) of the next century, regional interconnections of solar electric power generation would occur, and solar buildings might be sufficiently abundant to constitute an important modification of the electrical and fuel systems in which they were embedded. Solar fuel production facilities would be increasingly used, with truly largescale solar fuel production occuring in the second decade of the next century. In the first decade of the next century and beyond, continental dimensions would be involved in transport of electricity, permitting the linking of solar power plants over large distances and to regions not suitable for siting of such facilities.

This is of course only the barest of sketches, but it suggests something of the evolutionary process which such a system, if developed, would proceed through. Since local and regional applications would come first, it will be necessary to precede such developments with appropriate methodologies which permit the evaluation of the potential use for such technologies on a region by region basis. Variations in virtually every parameter determining the economic and production potential of solar options will occur at the regional level. The parameters include meteorological conditions, quality and extent of available land, the technical, economic and institutional structure of the local and regional utility systems, price and availability of other sources of energy, and an array of social and political priorities. No such methodology exists and, until it does, it is unlikely that we will be able to assess how the evolution to a global level of use could occur, nor where the important early prospects for solar energy conversion will be. 
Because of the need for such methodologies, and the need to assess the significance of a global solar option in advance of having it, a number of systems issues require further investigation. These are discussed in the subsequent sections.

EMBEDDING OF STOCHASTIC ENERGY SOURCES IN INTEGRATED ENERGY SYSTEMS

Solar conversion elements will be embedded in the larger integrated energy systems of society. Because of the possibility of continental and global transport of solar-derived fuels, coupled with the feasibility of long-term storage (several years), the behavior of large fuel systems will not be affected by short-term (daily, hourly, minute to minute) varlations in available sunlight. However, the siting of solar electric facilities will involve regions in which there are large stochastic variations in available sunlight, and in which bulk transport of electricity will be below $1000 \mathrm{~km}$ for several decades. Hence, one extremely important unsolved problem is the development of models which can permit simulation and optimization of the operation of electric utility systems containing solar power plants. In addition, models are required to guide investment decisions when capacity additions are required in response to demand forecasts. Such modeling would permit the following:

(1) determination of storage and/or backup generation capacity for a given utility system as a function of solar capacity on-line and of geographic deployment or siting strategies;

(2) clarification of systems reliability issues involving stochastic sources (direct solar, wind);

(3) determination of the degree to which accurate measurements of insolation in a region are required (i.e., what is the economic worth of various degrees of detail in insolation data?);

(4) establishment of a common methodological basis for intercomparison of electric generation methods region by region or utility by utility, including detailed determination of the economics of each option;

(5) permits assessment of the costs of solar electric power generation as a function of installed solar capacity in a particular grid;

(6) all of this, in turn, permits a more quantitative framework for public, political and industry discussion and decision-making regarding energy options. 
Recently the Aerospace Corporation [8] has undertaken pioneering work to establish the characteristics of integrated electric utility systems containing solar conversion elements. However, in their most recent report [9] for the Electric Power Research Institute, they point out that

there is no known and ytical method for establishing the optimum distribution of solar capacity between multiple sites.

In addition, they note that:
Another area which appears to merit further study is the method of dispatching all of the plants in a network which contains both solar and conventional capacity. Dispatching methodology needs to be developed which is suitable for use by a utility, and which minimizes both the total fossil fuel used and the amount of solar energy discarded when demand is low and storage is filled. This dispatching methodology should also permit other constraints (such as limits on polzutant emission) to be imposed on selected plants.

Figure 5 demonstrates the results obtained by Aerospace indicating the extent to which backup generation capacity is required as a function of solar capacity within a given utility system, but with alternate sites used for the plants. The dispersed system requires in the best case only half the backup generation (and associated costs) of the single site cases. A similar observation has been made by Soviet scientists [10], in which the amount of solar radiation available at a given confidence level was found to increase dramatically when many sites were "linked" together, as opposed to the conditions for the best single site investigated. Figure 6 illustrates an additional concern; that is the inter-relationship among solar and hydro-units in systems which contain both. Such systems could be of special importance in those countries in Europe (Austria or France, for example) in which high costs of fossil fuel make the possibility of coupled solar and hydro-systems of some interest [11].

It appears that the development of suitable models for integrated electric systems incorporating solar generation units is a major systems problem yet to be solved, and one whose solution will be required to determine the potential use of this option on a region by region basis. 


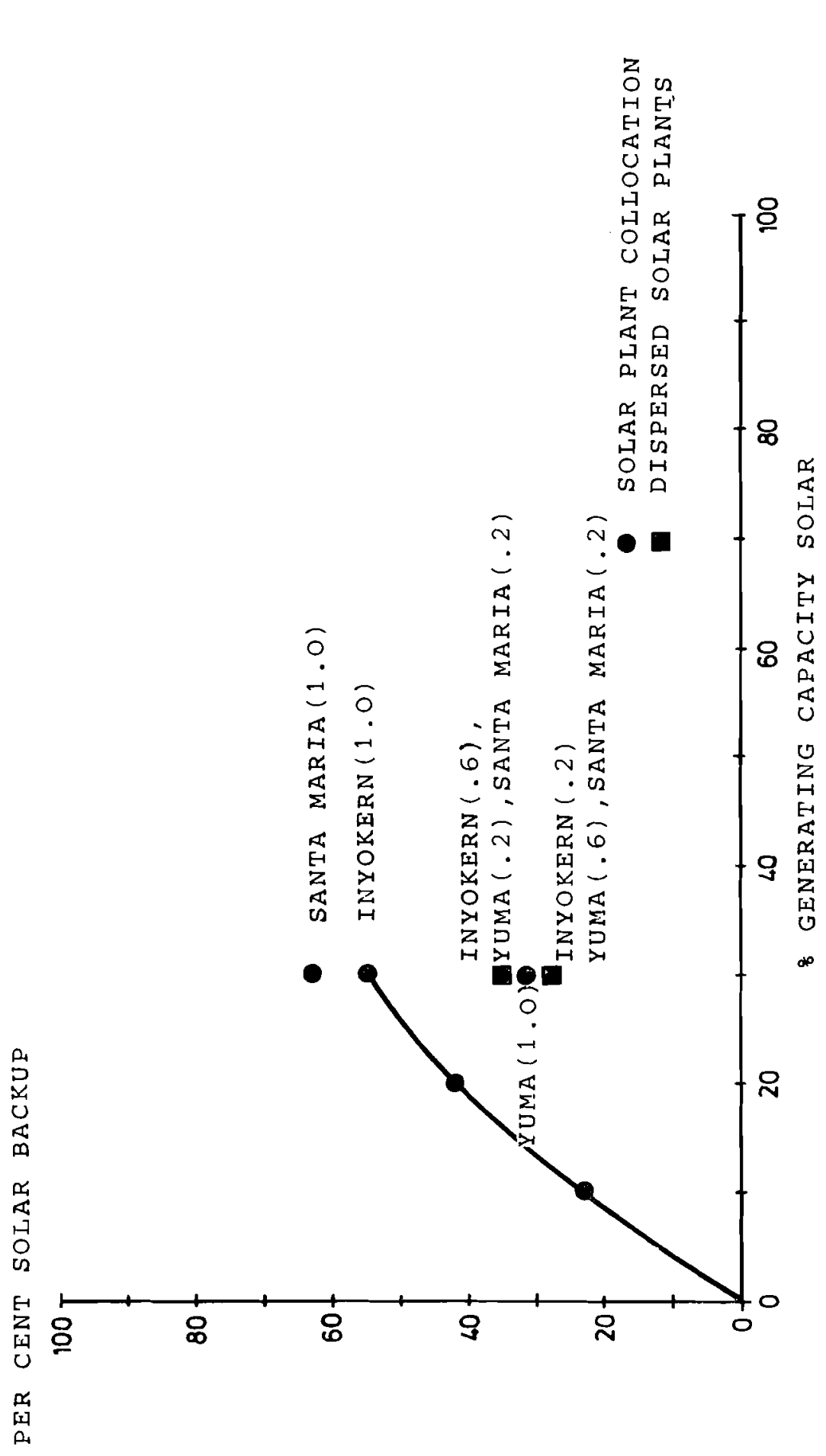

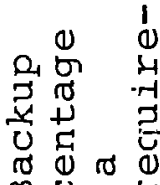

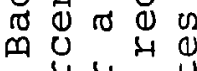
过 40 ० - 245 on नิ 0 प्षण

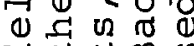
员故的 出荷 नि को Q द 10 व

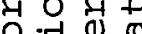
0 计

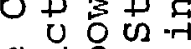
0 द

0 年 4 व

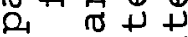
औ $07-7$

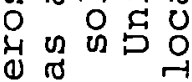
约岁害。 + क्ष 吃 $+\pi$ 元 तु

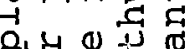
पद्व 4 它 उ म 4 ठ4 न ब

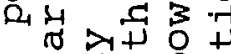
4 4 开

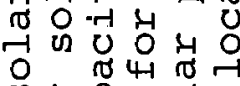
ज प्र०ि त्र 44000 0 , 0 4 겅뎡영 द O

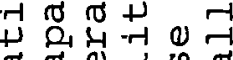
क 万人 पु द 0 \& ब दू б.ने 0 व + विन्न

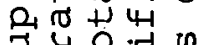
马엉 它记

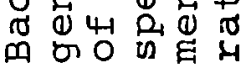

نं 


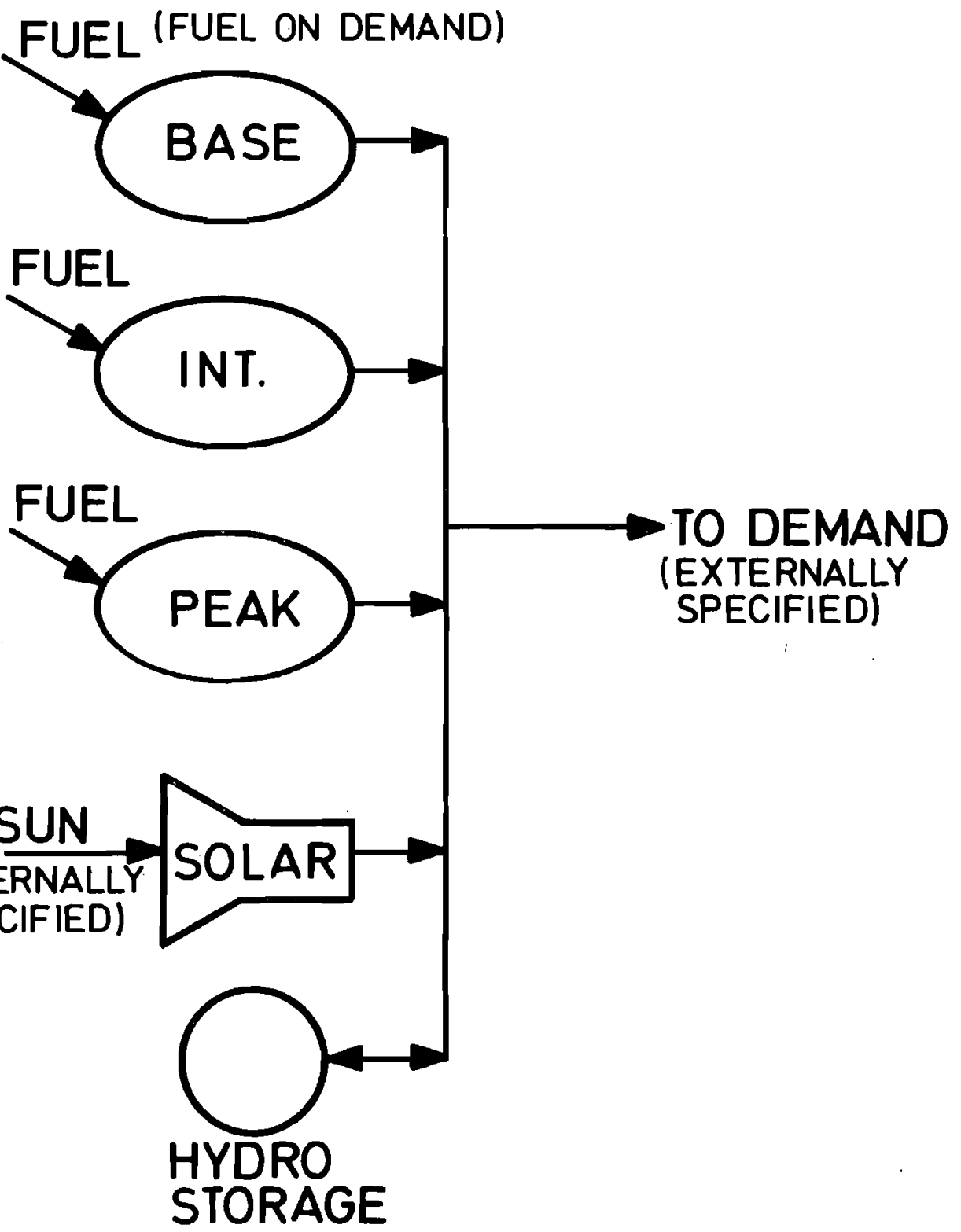

Figure 6. Simplified model integrated electrical utility system including solar electric conversion and pumped hydrostorage. Schematic representation of an integrated electric utility system combining solar power plants and hydroelectric storage with conventional generating units. The general problem of modeling and optimizing such a system remains to be solved 
EMBEDDING OF SOLAR FACILITIES IN THE LANDSCAPE

In principle, solar energy conversion over three to five per cent of the land could provide each nation in Europe wi: $\mathrm{h}$ its total current energy needs; smaller fractions arise when considering sunnier parts (Table 6) of the world, including emerging nations even in a highly developed future state. However, siting of solar facilities will be a complex process (schematically indicated in Figure 7) and will require formal technirues to carry it out efficiently and economically.

For example, formal procedures will be required to permit an assessment of the trade-offs involved in competition for land resources in regions of the world where such resources are under extreme pressure. Such procedures would permit a formalized guide (not necessarily a rule) for site selection

Table 6. Solar energy conversion and land use in the USA. Land area requirements for solar energy conversion and other uses in the United States. Half of the land area is used for solar energy conversion to food. Less than one per cent in additional land (arid wastelands) could provide the total energy needs of the us by solar energy conversion

\begin{tabular}{|c|c|c|c|}
\hline Region & $10^{6} \mathrm{~km}^{2}$ & $\%$ Total & $\mathrm{m}^{2} / \mathrm{cap}$ \\
\hline Continental & 5.86 & 100 & 26,600 \\
\hline $\begin{array}{l}\text { Cropland } \\
\text { Grassland pasture } \\
\text { Woodland pasture } \\
\text { Other woodland } \\
\text { Farmsteads, roads }\end{array}$ & $\begin{array}{l}0.95 \\
1.40 \\
0.16 \\
0.13 \\
0.07\end{array}$ & $\begin{array}{r}17.0 \\
24.0 \\
2.7 \\
2.2 \\
1.2\end{array}$ & $\begin{array}{r}4,500 \\
6,380 \\
718 \\
585 \\
319\end{array}$ \\
\hline $\begin{array}{l}\text { Grazing land } \\
\text { Forests } \\
\text { All other land }\end{array}$ & $\begin{array}{l}0.74 \\
1.23 \\
1.13\end{array}$ & $\begin{array}{l}12.7 \\
21.0 \\
19.3\end{array}$ & $\begin{array}{l}3,378 \\
5,586 \\
5,133\end{array}$ \\
\hline Solar Electric & 0.012 & 0.2 & 55 \\
\hline Solar Fuels & 0.038 & 0.64 & 170 \\
\hline Total Solar & 0.5 & 0.84 & 225 \\
\hline
\end{tabular}




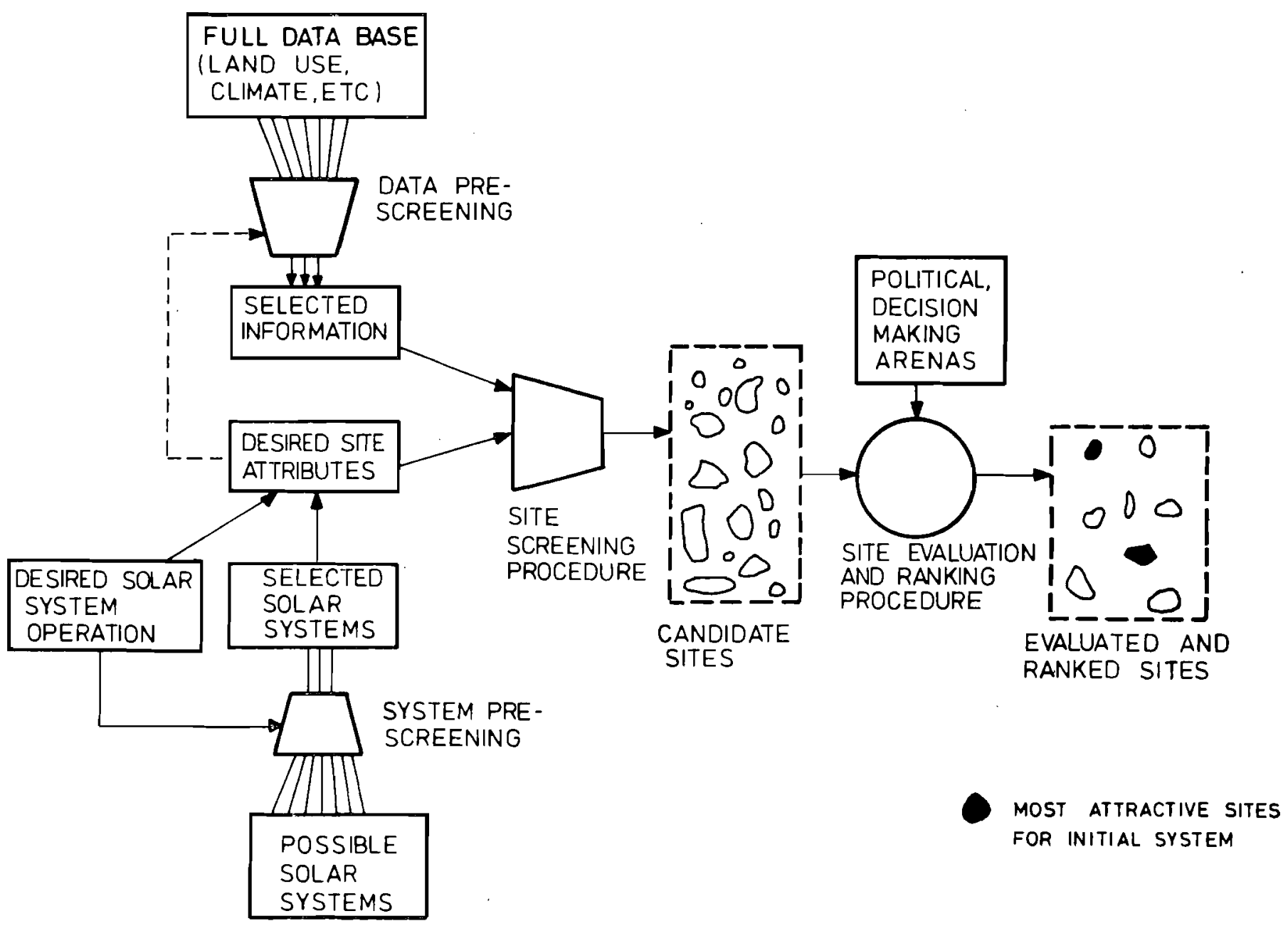

Figure 7. Solar energy conversion facility siting methodology. A schematic representation of the process required for identification and ranking of suitable sites for solar energy conversion facilities

when large numbers of solar facilities are contemplated; they would permit evaluation of alternative siting strategies when these alternative strategies had different costs associated. This will clearly be related to the results of analysis in which the effects of coupling the output of dispersed sites have been determined. In addition, such techniques will determine the extent to which land use is a real constraint. A recent study in Austria [11] indicates that it is feasible, in terms of available land, to consider a strategy in which four 
times the present electricity production of Austria is provided through a combination of solar electric power plants and hydro-storage units. This somewhat counterintuitive result arose from a systems perspective in which the entire Austrian electric system could be used for embedding solar electric facilities.

In addition, an organized siting procedure would permit advance designation of certain areas as potential sites, so as to keep "open" the solar option in a region. As an example of the effect of distributing solar generation capacity, Figures 8 and 9 show sunlight for two cities in Austria which are less than $50 \mathrm{~km}$ apart. The summing of the sunlight in the two regions "smoothes" the variation hour to hour, and suggests how a more detailed examination of multiple site combinations could considerably increase the predictablility of available sunlight.

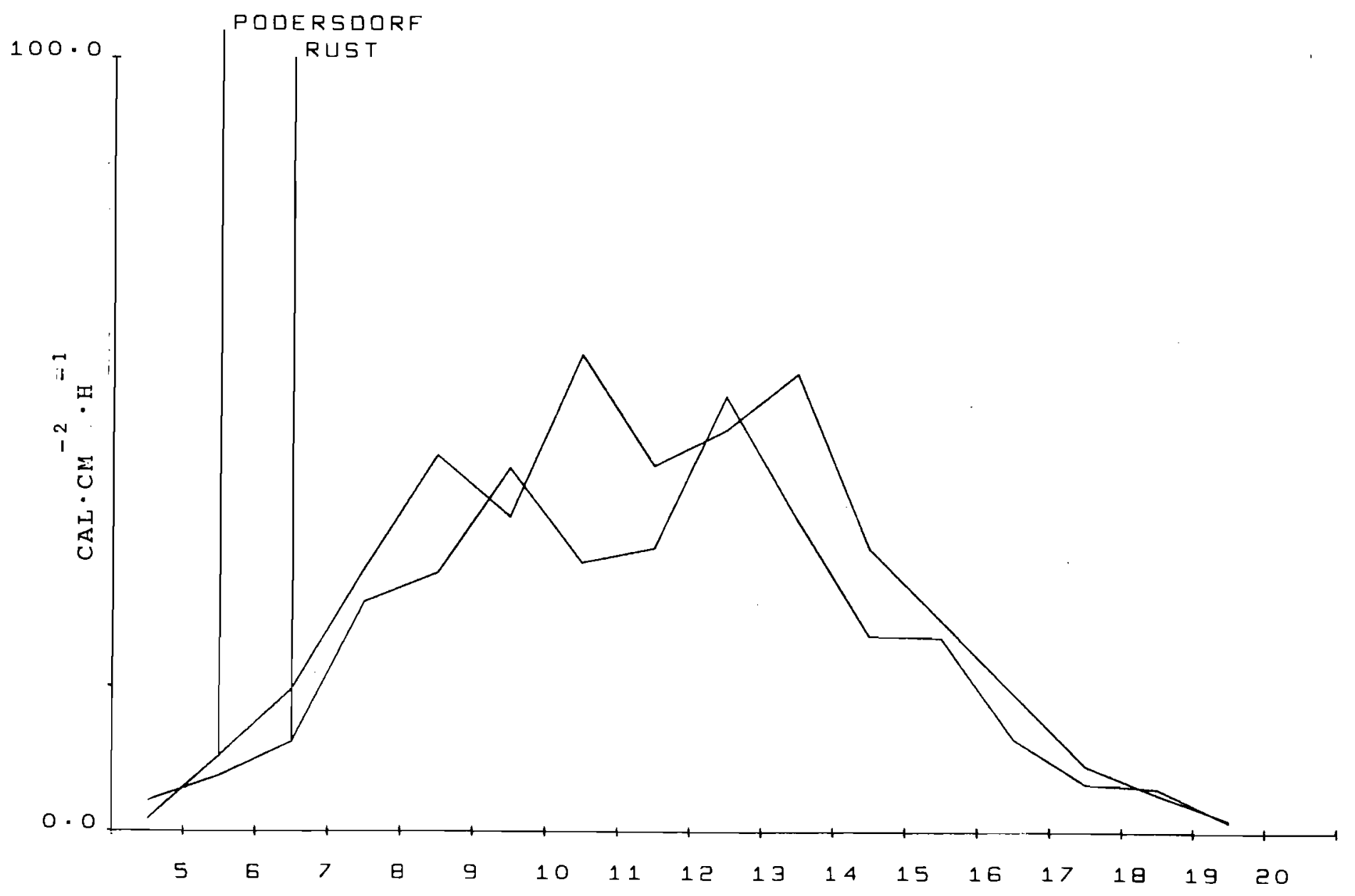

Figure 8. Global radiation by hour of day for 25. June 1969 . Hourly sunshine pattern for two cities in the same general region in Lower Austria 


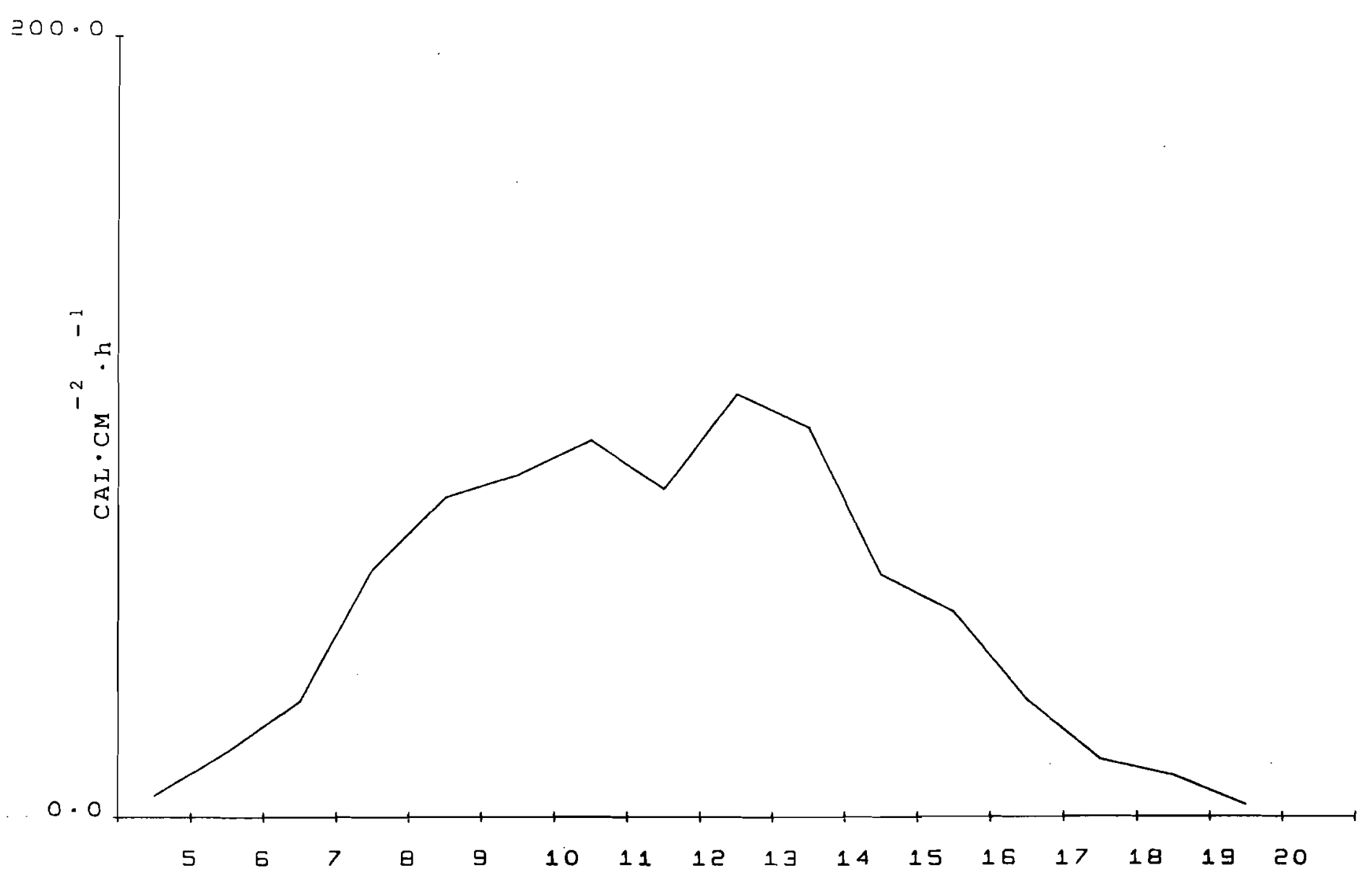

Figure 9. Global radiation by hour of day for 25 June 1969. Summed values for cities Podersdorf and Rust. Solar radiation at two sites (Rust and Podersdorf). in Austria, summed to simulate the interconnection of solar power plants at the two locations

As public concern over the environmental and social aspects of the siting of large industrial facilities grows, it will be increasingly important to provide a framework within which public and political discussion can take place. Again, a formalized procedure for characterizing and ranking various sites for solar facilities would be an important step towards resolving possible future conflicts over the siting of solar and related (i.e. storage) facilities. This "open planning" approach, to be successful, requires the underpinning of a systems analytic framework. 
MARKET PENETRATION DYNAMICS FOR NEW ENERGY SYSTEMS

A very important policy issue centers on the rate, scale and ultimate level of production we can expect from a new technological option, including new energy options including fission and solar systems. To have some well-founded sense of the maximum rate at which solar thermal, electric and fuel production options could be useful in various regions would be of enormous consequence in the present debate over solar and nuclear energy. In the United States some opponents of nuclear power have argued that solar energy conversion is an alternative; others proposing a nuclear dominated future have argued that the solar option can not be important for a very long time. We must quantify this discussion if anything useful concerning the relative market position of new energy options in the future is to be said.

Figure 10 demonstrates the present range of disagreement over both total energy demand and the possible role of solar energy conversion in the coming half century or so in the

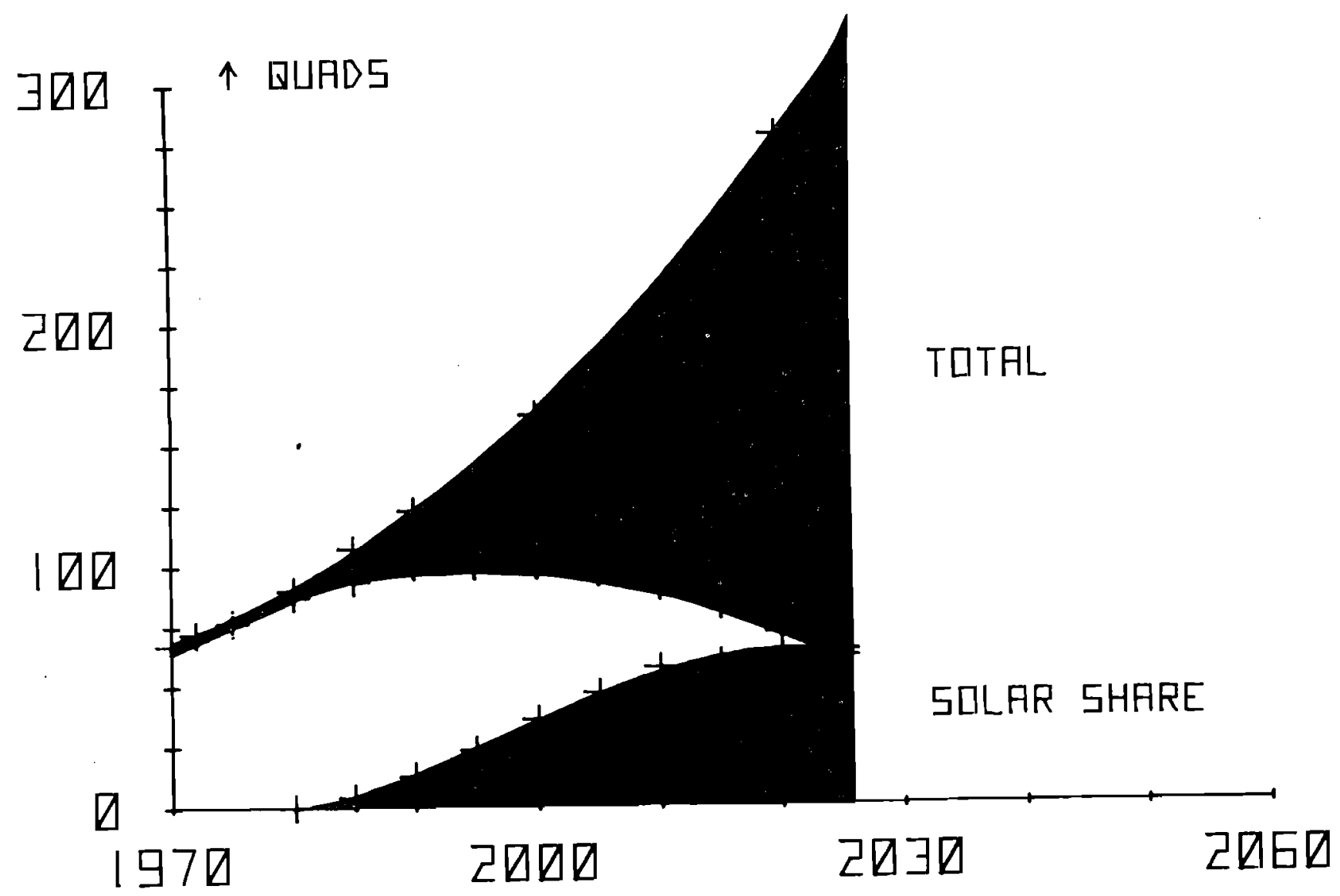

Figure 10. Scenario range for total us energy demand and the possible contributions from solar energy 
United States. The upper part of the total demand range corresponds to three per cent per year growth; the lowest projection corresponds to a recent scenario by A.B. Lovins [12, 13]. Similarly the projections for the maximum possible contribution from solar energy use (both direct and indirect uses) range from essentially no contribution to the maximum curve corresponding to a number of enthusiastic projections by A.B. Lovins [12], the MITRE Corporation [14] and others. The large number of projections have been made by various indiviuuals and institutions using a variety of techniques. In some cases the projections are actually formal program goals; in others they are the results of various types of model calculations such as those presented by the stanford Research Institute [15]; in yet others they appear to be produced by intuition.

We need something better. The dynamics of large, complex, highly interconnected systems (national economies) constrain the rate at which some new option can enter the marketplace, including the energy market. J.C. Fischer and R.H. Pry [16] discovered that the process of technological substitution, in which one product or process displaces its more traditional competitor, invariably occurs with a smooth and simple behavior. They found that the substitution of synthetic rubber for natural rubber, water-based for petroleum-based paints, electric for open hearth steel making, and many other examples, all occurred in a logistic fashion, in which the penetration or market fraction captured by the "intruder" was given by

$$
\ln (f / 1-f)=K\left(t-t_{0}\right) \text {, }
$$

where

$f$ is the fraction of the total market captured by the new competition;

$t_{0}$ is the date at which $f$ equals 0.5 ;

$K$ is a rate constant.

C. Marchetti [17] has extended this approach to that of the energy marketplace, and has discovered that the rate of entrance and departure of various energy sources into and out of the energy marketplace is essentially logistic. This relationship appears to hold rather well over a period of a century or more worldwide, for the United States, and (for shorter periods, due to lack of long-term data) for many other countries as well. This remarkable behavior is shown in Figure 11 in which the market shares for wood, coal, oil and natural gas are shown with their logistic counterpart. The growth projection for fission is based on optimistic projections but is probably not inconsistent with purely technological capabilities. The projection for solar energy is based on the assumption that a variety of large-scale solar technologies 


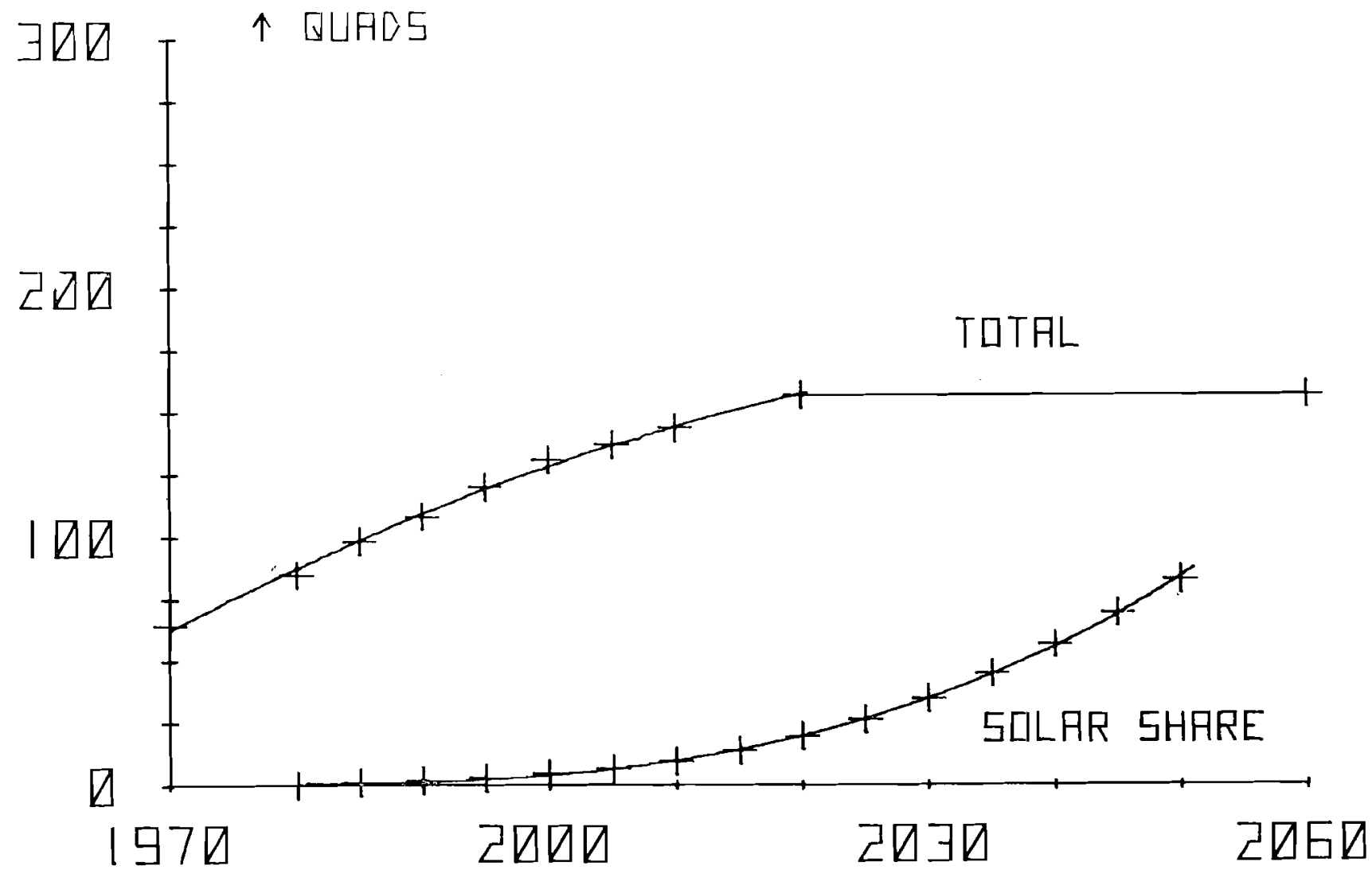

Figure 11. Logistic scenario for the use of solar energy in the United States to displace other sources of energy, developed by Weingart and Nakicenovic, IIASA

can enter the US energy market in the early 1980's and before, and grow to displace 25 per cent of the total primary energy demand by the year 2030. This would correspond to solar energy displacing other primary sources (of secondary energy) at a fractional rate exceeding that with which oil and natural gas entered the market. Such a scenario in itself is optimistic and assumes technical, economic and institutional success for large-scale solar technologies within the coming decade to two decades. Such a projection, when overlaid on any reasonable 
scenario for total energy demand, indicates that it is highly unlikely that any new energy technology entering the marketplace in the 1980's can have a substantial contribution until some four decades later. (Such a scenario for total demand and the fractional solar share developed by $J$. Weingart and N. Nakicenovic [18] is shown in Figure 12.) Yet many scenarios, including those of ERDA, Lovins, the MITRE Corporation-which preshadowed the major US effort in solar energy conversion--are all far more optimistic than this. If indeed the properties of national economies are "smooth", due to their size and complexity, we need to understand the implications of ahistoric departures from what have been well-behaved patterns of change in the past. We do not say that the more optimistic scenarios are "wrong" or impossible; we do point out that they are sufficiently inconsistent with previous behavior to provoke us to inquire into the reasons (the "hidden variables", if you will) behind the smooth external behavior of the economic system. The entire area of the dynamics of the penetration of new technologies into traditional markets is a very rich one for systems analysis and a necessary one for the development of realistic policy for the development and widespread use of new technologies.

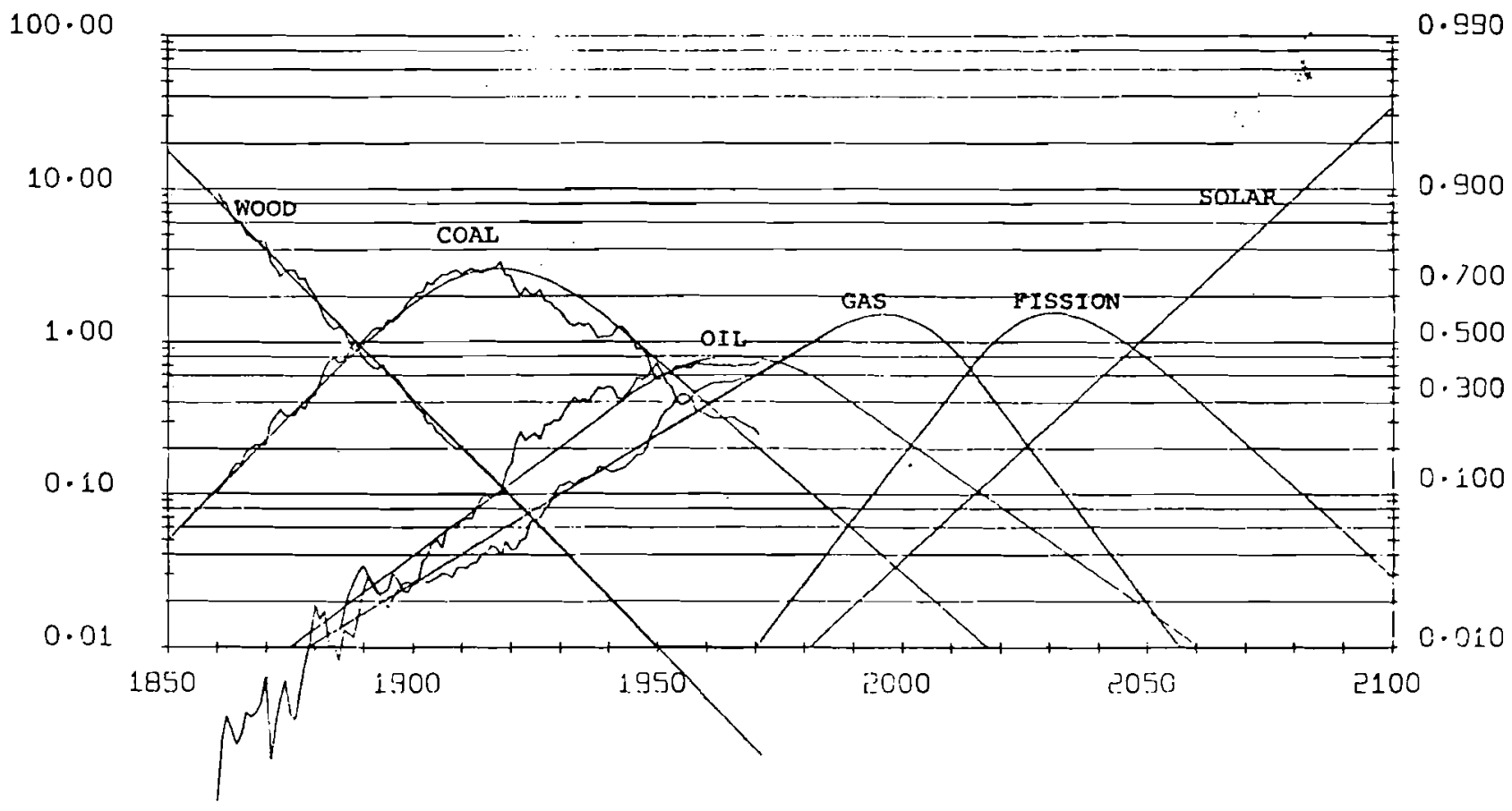

Figure 12. Logistic fit and projections for primary energy use in the United States, 1850 - 2100. Based on work of Marchetti and Nakicenovic at IIASA 
In addition to arguments over the rate at which some new energy technology can be made available, there are fundamental disagreements over how the attributes of alternative energy futures can be compared. How, for example, does one weigh the perceived risks of reactor safety, radioactive waste management and the possibility for terrorist disruption of a nuclear energy system (and society) against the perhaps higher direct costs, larger requirements for land and materials, and requirements for remote siting (in the asymptotic phase of deployment) of a solar conversion systern? Acknowledging the considerable disagreement in the magnitude of such attributes as reactor safety, it is nevertheless clear that we have no widely accepted or used formal procedure for intercomparing qualitatively different energy systerns options, even if agreement on these other issues were possible. There is a need to bring some formal systems techniques, such as decision analysis, into the larger debate over future energy strategies, if only to clarify what it is we are disagreeing about, and perhaps to facilitate consensus when a decision to initiate new energy production systems is required. We should be prepared, however, for situations in which consensus will be impossible and in which there will be little chance of widespread agreement or even compromise on the use of a specific technological option. This now appears to be the case in the nuclear debate in the United States, and it is probably true in much of Western Europe where the overall energy situation is much more critical. In the absence of a clear strategy for transition from fossil to non-fossil energy sources, and in the face of the inevitable need to initiate and carry out that transition (and the hour is growing late) we will have to develop strategies which can absorb the disagreement and problems and permit the transition to occur. This brings us to the final consideration of this paper, that of the "resilience" of future energy stragegies.

\section{RESILIENT ENERGY STRATEGIES}

Biologists have known for decades that complexity and diversity in natural ecosystems are in some way closely linked to the ability of such systems to persist in the face of unexpected and sometimes previously unexperienced assaults. R. Dubos has often noted that there is an analogy for human ecosystems--that societies which have developed a multiplicity of options for achieving social goals appear to persist longer than societies which are dependent on a single mode of accomplishing a central activity of society.

In the case of the human species there can be little doubt that the species itself will survive, even after the most terrible holocausts. As the biologist F. Smith has said [19]: 
the problem is that we are doomed to survive. What we are clearly after is not the survival of mankind as a species, but mankind as a dynamic, polycultural system in which the quality of the human experience is continuously improved.

It therefore is desirable and probably necessary to design our technological systems, including energy, in such a way that inevitable fluctuations in personal and social behavior, as well as natural disasters, do not seriously impair the functioning of a vital human society. We would like to somehow insure our ability to make progress in spite of ourselves. That is, we need to design our future strategies to be "resilient".

C.S. Holling [20] has defined resizience as the ability of a system to absorb external forces and persist. Such systems can change in such a way that permits the assimilation of shocks without destruction, unlike brittle systems which have a threshold for assault, after which they collapse completely. Military strategists have long. used J. von Neumann's concept of functional redundancy in the design of weapons systems in which a specific function is carried out in parallel by a number of functionally identical but physically very different subsystems. A specific example would be coupling inertial guidance, fluidic, and electronic subsystems into the guidance system of a missile. Destruction of the electronic components by a nearby intense radiation field would not damage the purely mechanical components, permitting the function to continue. Although this example is not a happy one to contemplate, it demonstrates where systems are considered by their designers to have to succeed in the face of multiple assaults, techniques for creating a high degree of resilience have been used.

Such considerations are directly relevant to future energy strategies. If we extend the analogy, there should be intense effort at the parallel development of a multiplicity of physically different, functionally identical energy systems options. This means, in short, the use of the remaining fossil fuels, notably coal, along with fission, fusion, geothermal and solar sources to produce identical secondary enerqy vectors, for example heated fluids on a small scale, electricity and synthetic fuels on a larger scale. Failure to develop one or two, or even three, of the long-term options would still permit large-scale energy production. However, the successful development of several of these options would provide a high degree of resilience in a world energy system.

We would like to create a world energy system in which, for example, large-scale embargo was structurally impossible, in which synthetic fuels could be stored sufficiently to permit a smooth response to both man-made and natural disasters, 
and one in which there were no continual, possibly destructive, impact on natural ecosystems and climate. We would like to have, once and for all, an assured and adequate source of energy so that the really important human issues could be addressed at the global scale.

As discussed earlier, a global solar energy system would appear to have all the important attributes of a highly resilient global energy system, including the quality of being "safe-fail" rather than "fail-safe". A solar power plant could be destroyed wi.th no direct effect on society, unlike the case of a power reactor catastrophe. Nuclear systems must be fail-safe, since their failure, given present siting strategies, would in many cases be catastrophic.

A combined solar/nuclear(fission) system, evolving from the regional and national to the global scale, might be even more resilient than the solar system alone, at least for the next half century. The market penetration analysis indicates that under the best of circumstances fission systems will be required if the use of fossil fuels is to be substantially moderated; only after some four decades could the solar options really take over. In any case, the development of a multiplicity of energy system options which can function together would appear to buy us an insurance policy against the inevitable large uncertainties of the future.

At IIASA there has been a strong interest in somehow formalizing the concept of resilience [21]. Here an extremely important policy issue emerges and again serves to challenge the systems analysis community. How can we somehow quantify the concept(s) of resilience and measure the characteristics of a multi-source energy system against one in which only a single source is dominant? How can we evaluate the benefits of a clearly very expensive policy of developing solar, fission, fusion and geothermal options in parallel? Can such an evaluation be made in a satisfactory formal way and can the results be translated into the policy area? Can we develop techniques to help us design resilient strategies for the future to help us deal with the unknown? This may be far superior than attempting to predict the future by mandate. After all, making predictions is very difficult observed N. Bohr, especially about the future. 


\section{$\underline{\text { References }}$}

[1] Doxiadis, C.A., and J.G. Papaionannou, Ecumenopolis - The Inevitable City of the Future, Center for Ekistics, Athens, 1974.

[2] Hëfele, W., et al., Second Status Report of the IIASA Project on Energy Systems, 1975, RR-76-1, International Institute for Applied Systems Analysis, Laxenburg, Austria, 1976 .

[3] Häfele, W., and W. Sassin, the Global Energy System, in J.M. Hollander, ed., Annual Review of Energy, vol. 2, Annual Reviews, Inc., Palo Alto, Ca., 1977.

[4] Marchetti, C., Transport and Storage of Energy, RR-75-38, International Institute for Applied Systems Analysis, Laxenburg, Austria, 1975, and Marchetti, C., From the Primeval Soup to World Government: An Essay on Comparative Evolution, RR-76-9, International Institute for Applied Systems Analysis, Laxenburg, Austria, 1976.

[5] Williams, J., G. Krömer, and J. Weingart, eds., Proceedings of the International Workshop on Potential Impacts of Solar Energy Conversion on Weather and Climate, International Institute for Applied Systems Analysis, Laxenburg, Austria, (in preparation).

[6] Duffie, J., and W. Beckman, Solar Energy Thermal Processes, John Wiley and Sons, New York, 1975.

[7] Definition Report - National Solar Energy Research, Development and Demonstration Program, ERDA-49, Energy Research and Development Agency, Division of Solar Energy, Washington D.C., 1975.

[8] Solar Thermal Conversion Mission Analysis, ATR-74 (7417-16) -1, IV, Aerospace Corporation, El Segundo, Ca., 1974.

[9] The Aerospace Corporation, Penetration Analysis and Margin Requirements Associated with Large-Scale Utilization of Solar Power Plants, ER-198, 1976.

[10] Tarnizhevskii, B.V., and A.N. Smirnova, Generation of Electric Power at High Reliability Levels using a Group of Solar Power Plants in an Energy System, Geliotekhnika, 10, $5(1974), 36-43$. 
[11] Weyss, N., Some Aspects of the Solar Case Study Austria Illustrated by the Example of Hybrid Power Plants, in W. Häfele, et al. [2].

[12] Lovins, A.B., Energy Strategy: The Road not Taken?, Foreign Affairs 55, 1(1976), 65-96.

[13] Lovins, A.B., Scale, Centralization, and Electrification in Energy Systems, paper held at the Symposium on Future Strategies of Energy Development, Oak Ridge, Tenn., $20 .-21.10 ., 1976$.

[14] The MITRE Corporation, Systems Analysis of Solar Energy Programs, MTR-6513, National Technical Information Service, Springfield, Va., 1973.

[15] A preliminary Social and Environmental Assessment of the ERDA Solar Energy Program 1975-2020, Stanford Research Institute report to the Environmental and Resources Study Branch, Division of Solar Energy, Energy Research and Development Administration, Washington, D.C., (in press).

[16] Fisher, J.C., and R.H. Pry, A Single substitution Model of Technological Change. Technical Information Series, Report 70-C-215, General Electric Company, Corporate Research and Development, Schenectady, New York, 1970.

[17] Marchetti, C., On Strategies and Fate, in w. Häfele, et al [2].

[18] Weingart, J., and N. Nakićenović, Market Penetration Dynamics and the Large-Scale Use of Solar Energy, International Institute for Applied Systems Analysis, Laxenburg, Austria, (in preparation).

[19] Smith, F., remarks made at a conference on the human environment, California Institute of Technology, 1971.

[20] Holling, C.S., Resilience and Stability of Ecological Systems, RR-73-3, International Institute for Applied Systems Analysis, Laxenburg, Austria, 1973, see also C.S. Holling, Myths of Ecology and Energy, in A.B. Lovins, [14].

[21] Grümm, H.R., ed., Analysis and Computation of Equizibria and Regions of Stability, with Applications in Chemistry, Climatology, Ecology and Economics, Record of a Workshop, CP-75-8, 1975; see also

H.R. Grümm, Definitions of Resilience, RR-76-5, International Institute for Applied Systems Analysis, Laxenburg, Austria, 1976. 